\title{
Impact of weight maintenance and loss on diabetes risk and burden: a population- based study in 33,184 participants
}

\author{
Adina L. Feldman', Simon J. Griffin', Amy L. Ahern', Grainne H. Long1', Lars Weinehall², Eva Fhärm²,
} Margareta Norberg ${ }^{2}$ and Patrik Wennberg ${ }^{2 *}$

\begin{abstract}
Background: Weight loss in individuals at high risk of diabetes is an effective prevention method and a major component of the currently prevailing diabetes prevention strategies. The aim of the present study was to investigate the public health potential for diabetes prevention of weight maintenance or moderate weight loss on a population level in an observational cohort with repeated measurements of weight and diabetes status.

Methods: Height, weight and diabetes status were objectively measured at baseline and 10 year follow-up in a population-based cohort of 33,184 participants aged 30-60 years between 1990 and 2013 in Västerbotten County, Sweden. The association between risk of incident diabetes and change in BMI or relative weight was modelled using multivariate logistic regression. Population attributable fractions (PAF) were used to assess population impact of shift in weight.
\end{abstract}

Results: Mean (SD) BMI at baseline was $25.0(3.6) \mathrm{kg} / \mathrm{m}^{2}$. Increase in relative weight between baseline and followup was linearly associated with incident diabetes risk, odds ratio (OR) 1.05 (95\% confidence interval (CI) 1.04-1.06) per $1 \%$ change in weight. Compared to weight maintenance $\left( \pm 1.0 \mathrm{~kg} / \mathrm{m}^{2}\right)$, weight gain of $>+1.0 \mathrm{~kg} / \mathrm{m}^{2}$ was associated with an increased risk of incident diabetes, OR $1.52(95 \% \mathrm{Cl} 1.32,1.74)$, representing a PAF of $21.9 \%$ (95\% Cl 15.8, 27.6\%). For moderate weight loss $\left(-1.0\right.$ to $\left.-2.0 \mathrm{~kg} / \mathrm{m}^{2}\right)$ the OR was $0.72(95 \% \mathrm{Cl} 0.52,0.99)$.

Conclusions: Weight maintenance in adulthood is strongly associated with reduced incident diabetes risk and there is considerable potential for diabetes prevention in promoting this as a whole population strategy.

Keywords: Body mass index, Body weight change, Diabetes mellitus, Public health, Epidemiology

\section{Background}

Since the positive outcome of several large scale trials demonstrated that lifestyle interventions among individuals at high risk for diabetes are effective for reducing disease incidence [1] the high-risk strategy has been the policy paradigm for prevention of diabetes [2, 3]. In many of the successful trials, weight reduction was a key component of the intervention [4, 5]. Indeed, the association between excess weight defined as overweight $\left(\right.$ BMI $\left.\geq 25.0 \mathrm{~kg} / \mathrm{m}^{2}\right)$ and obesity (BMI $\left.\geq 30.0 \mathrm{~kg} / \mathrm{m}^{2}\right)$, and increased incident diabetes risk is well established [6].

\footnotetext{
* Correspondence: patrik.wennberg@umu.se

2Department of Public Health and Clinical Medicine, Umeå University, 90187 Umeå, Sweden

Full list of author information is available at the end of the article
}

The association between BMI and incident diabetes appears to be approximately linear [7], making BMI a suitable candidate target for a population shift strategy, as proposed by Rose [8]. However, it is unknown how big such a shift would need to be to affect a substantial impact on the occurrence of diabetes in the population.

The potential public health impact of targeting a specific risk factor in the population is usually assessed by estimating the population attributable fraction (PAF), which is the proportion of cases that could be prevented if the risk factor, such as excess weight or weight gain, was eliminated. With regards to body weight and diabetes, most studies have focused on the potential impact on diabetes occurrence of eliminating excess weight $\left(\right.$ BMI $\left.\geq 25.0 \mathrm{~kg} / \mathrm{m}^{2}\right)$ in the population. There has been 
considerable variability in the methods used to estimate these PAFs [9] which have ranged from 3\% in women in the Framingham study [10], to $77 \%$ in a Finnish population [11]. However, as the probability that obese adults will attain normal weight is exceedingly low [12], a more realistic approach may be to study the potential population impact of achievable reductions in body weight, or of preventing weight gain $[13,14]$. There is considerable evidence concerning the association between weight gain at a population level and diabetes risk [15], but there is much less evidence concerning the risk and public health impact associated with moderate weight loss or primary weight maintenance (i.e., prevention of weight gain in adulthood). In addition, compared to the evidence for individual high-risk approaches, there is a dearth of evidence concerning population-based approaches for diabetes prevention. We aimed to investigate the public health potential of a whole population strategy for diabetes prevention by quantifying the impact on risk and population burden of diabetes of shifting the population distribution of body weight. To this end we used data from a large cohort study with objective longitudinal measures of weight and diabetes status.

\section{Methods}

\section{Study population}

The Västerbotten Intervention Programme (VIP) was initially established in 1985 as a community and individual-level programme to reduce the morbidity and mortality from cardiovascular disease in Northern Sweden [16]. The programme has evolved with the development of new national and international guidelines and methods, but the basics have remained the same. Participants are invited to their primary care centre during the year of their $30^{\text {th }}$ (until about 1995), $40^{\text {th }}, 50^{\text {th }}$, and finally $60^{\text {th }}$ birthday for standardised health examinations including oral glucose tolerance tests (OGTT). For individuals found to have a BMI $\geq 30 \mathrm{~kg} / \mathrm{m}^{2}$ the recommendation is that the attending health care practitioners provide counselling concerning lifestyle changes aimed at risk factor reduction, and those found to have Impaired Glucose Tolerance (IGT) are referred for a follow-up visit with a nurse, generally every second year (as with those found to have Impaired Fasting Glycaemia (IFG) after the concept was introduced in 2003) [16]. At every VIP visit the participants are asked to complete a comprehensive questionnaire that covers among other things lifestyle behaviour, health, and psychosocial status. Baseline participation rate over the study period has ranged from 48 to $67 \%$ of eligible people [16].

The data collected in VIP was used to conduct an observational prospective cohort study. All individuals first included in VIP between 1990 and 2003 at age 30, 40 or 50 were eligible to be included in the study population $(n=52,889)$. After excluding those who had prevalent diabetes at baseline $(n=1,280)$, missing baseline OGTT $(n=433)$ or who did not participate in the 10-year follow-up $(n=14,980), 36,196$ participants with followup remained (70.7\% of baseline participants). As diabetes patients are likely to lose weight following a diagnosis [17], we excluded participants who self-reported diabetes at follow-up $(n=487)$ to limit potential bias due to reverse causation. We also excluded all participants who at follow-up had missing OGTT data $(n=29)$. Finally, we excluded participants with missing, incomplete or erroneous data on weight and/or height $(n=1073$, see details below) or missing data on any co-variate $(n=$ $1,423)$, leaving a final study population of 33,184 participants with complete data available for analysis (Additional file 1: Figure S1). Written informed consent was obtained from VIP participants and ethical approval was granted by the Regional Ethical Review Board, Umeå University [Dnr 08-131 M].

\section{Assessment of diabetes}

The outcome was newly detected diabetes at 10 year follow-up based on OGTT with a $75 \mathrm{~g}$ oral glucose load and measurements of fasting and 2-h capillary plasma glucose. Diabetes was defined as having fasting glucose $\geq 7.0 \mathrm{mmol} / \mathrm{L}$ or 2 -h glucose of $\geq 12.2 \mathrm{mmol} / \mathrm{L}$ $[18,19]$. For descriptive purposes we also defined IGT: fasting glucose $<7.0 \mathrm{mmol} / \mathrm{L}$ and 2 -h glucose $\geq 8.9-<$ $12.2 \mathrm{mmol} / \mathrm{L}$, and IFG: fasting glucose $\geq 6.1-<7.0 \mathrm{mmol} / \mathrm{L}$ and 2-h glucose $<8.9 \mathrm{mmol} / \mathrm{L}$.

\section{Assessment of anthropometric data}

Height and weight were measured in light clothing at the health examination at baseline and 10 year followup, and BMI was calculated as weight in kilograms $(\mathrm{kg})$ divided by height in metres (m) squared. Except for small diurnal variation, people aged $30-50$ years do not normally increase in height over 10 years follow-up, but some decrease in height may be expected [20]. To avoid unreasonable variation in BMI due to height measurement error or data entry error, we excluded all participants with larger than expected variation in height between baseline and follow-up (height gain $>2$ centimetres $(\mathrm{cm})$ or height loss $>2,>3$ or $>4 \mathrm{~cm}$ for those aged 30, 40 and 50 years, respectively). In addition, we excluded participants with BMI $<10.0 \mathrm{~kg} / \mathrm{m}^{2}$, or with an increase or decrease in BMI of $>20.0 \mathrm{~kg} / \mathrm{m}^{2}$ between baseline and follow-up. In total we excluded 1073 participants due to missing or erroneous height and/or weight data (see above).

Relative weight change was calculated as percent change relative to baseline weight (((Weight 10year $_{\text {- }}$ Weight $_{\text {baseline }} /$ Weight $\left._{\text {baseline }}\right) * 100$ ). Absolute BMI change was calculated as $\left(B M I_{10 \text { year }}-B M I_{\text {baseline }}\right)$ in $\Delta \mathrm{kg} / \mathrm{m}^{2}$. 
Weight maintenance between baseline and follow-up was defined as relative weight change $\pm 3.0 \%$ of baseline weight [21], or as BMI change $\pm 1.0 \mathrm{~kg} / \mathrm{m}^{2}$.

\section{Assessment of other variables}

Tobacco use was dichotomised as tobacco use (smoking or use of moist snuff,) or no current tobacco use. Marital status was dichotomised as married/cohabiting or single/divorced/widowed. Family history of diabetes was defined as presence of diabetes in any parent or sibling. Educational level was categorised as primary (mandatory only), any secondary or any tertiary. These variables were self-reported in the baseline VIP questionnaire.

\section{Statistical analysis}

The association between the outcome, incident diabetes at 10 year follow-up, and within-individual change in weight and BMI was assessed using logistic regression generating odds ratios (OR) and 95\% confidence intervals $(\mathrm{CI})$. Four models were used to analyse the data: 1) BMI at 10 year follow-up was modelled as a categorical variable $(<25.0 ; 25.0-29.9 ; 30.0-34.9 ; \geq 35.0 \mathrm{~kg} /$ $\mathrm{m}^{2}$ ) stratified by baseline BMI category, with staying in the same category as the reference; 2) Absolute BMI change between baseline and 10 year follow-up was modelled as a continuous variable stratified by baseline age and BMI category; 3) Relative weight change between baseline and 10 year follow-up was modelled as a categorical variable (> $+7.0 \%$; +3.0 to $+7.0 \%$; $\pm 3.0 \%$; -3.0 to $-7.0 \%$; > $-7.0 \%$ ) stratified by baseline BMI category, with weight maintenance as the reference.; 4) Relative weight change between baseline and 10 year follow-up was modelled as a continuous variable, overall and stratified by baseline BMI category. Weight change categories were based on an established definition for weight maintenance [21], and gain or loss of $5 \pm 2 \%$. Stratification was achieved by including an interaction term between baseline BMI category and the exposure. Linearity in models 2 and 4 was tested by introducing a quadratic term. All models were adjusted for BMI at baseline (continuous) and the co-variates known to be associated with body weight and diabetes; sex, age at baseline (30, 40 or 50 years), calendar year at baseline (continuous), educational level, marital status, family history of diabetes and tobacco use. As a sensitivity analysis we excluded participants who were classified as underweight $\left(<18.5 \mathrm{~kg} / \mathrm{m}^{2}\right)$ at baseline. To assess the impact of weight or BMI change on the cumulative 10-year incidence of diabetes in the population we estimated PAFs with 95\% CI using the "punafcc" command in Stata. For calculating PAFs the modelled counterfactuals were: weight maintenance vs. any gain (i), moderate weight loss vs. maintenance or any gain (ii), and large weight loss vs. moderate loss or maintenance or any gain (iii).
PAFs were calculated using the formula ( $p d^{*}((\mathrm{OR}-1)$ ) $O R)$ ) [22] where $p d$ is the proportion of incident diabetes cases with the exposure (e.g., those with any weight gain in (i)) and OR is assumed to be a suitable approximation of the risk ratio (RR) due to the low prevalence of the outcome [23]. All data were analysed using Stata v. 13 for Windows.

\section{Results}

The mean BMI in the study population was 25.0 (median 24.6, interquartile range (IQR) 22.5-26.9, standard deviation (SD) 3.6$) \mathrm{kg} / \mathrm{m}^{2}$ at baseline and 26.3 (median 25.8, IQR 23.5-28.4, SD 4.1) $\mathrm{kg} / \mathrm{m}^{2}$ at 10 year follow-up (Table 1, Fig. 1). At baseline, $55.2 \%$ of the participants had a normal BMI $\left(<25.0 \mathrm{~kg} / \mathrm{m}^{2}\right)$ which fell to $41.2 \%$ at 10 year follow-up. In total, $1.1 \%(n=355)$ of participants were ever classified as underweight $\left(<18.5 \mathrm{~kg} / \mathrm{m}^{2}\right)$. Overall, $29.1 \%$ of participants maintained their weight $( \pm 3 \%)$ during followup, $56.6 \%$ gained weight and $14.2 \%$ lost weight.

Overall, 1087 incident diabetes cases were newly detected at 10 year follow-up, constituting 3.3\% of the study population (Table 2). Among the incident diabetes cases, $33.4 \%$ had had IGT or IFG at baseline (data not shown). The crude proportion of participants with incident diabetes increased substantially with age, BMI category, and relative weight increase. In addition, men experienced a higher crude diabetes risk than women.

Modelled predicted diabetes risk increased linearly with increase in relative weight change during follow-up in all BMI categories (Fig. 2). Participants with higher BMI at baseline had a higher absolute risk of diabetes but there was no significant difference in relative risk associated with change in relative weight between BMI categories at baseline ( $p=0.182$ for interaction). Overall OR for the linear association with diabetes risk per $1 \%$ change in weight was 1.05 (95\% CI 1.04, 1.06) (data not shown). There was no evidence of nonlinearity in the association between relative weight change and diabetes risk ( $p=0.980$ for quadratic term). There were no differences in relative risk of diabetes between those aged 40 or 50 years at baseline. With the exception of the highest BMI category, there was no association between BMI change and diabetes risk in the youngest participants who were aged 30 years at baseline (ORs 1.11, 1.14 , and 1.08 per unit BMI change, for baseline BMI categories <25.0, 25.0-29.9, and 30.0-34.9, respectively). In the lowest BMI category there was no association between diabetes risk and relative weight reduction $(-3.0$ to -7.0 or $>-7.0 \%)$ vs. weight maintenance, whereas there was a substantially increased risk associated with relative weight gain (OR 2.18, 95\% CI 1.63, 2.93 for $>+7.0 \%$ weight change). In the highest BMI category there was no association between relative weight gain and diabetes risk but a strong association with 
Table 1 Descriptive statistics of study population including all participants with 10 year follow-up, free of prevalent diabetes at baseline and with complete data. Västerbotten Intervention Programme 1990-2013

\begin{tabular}{|c|c|c|c|c|c|c|c|c|c|c|}
\hline \multirow[b]{3}{*}{$\overline{\text { Total }(n, \%)^{a}}$} & \multicolumn{10}{|c|}{ BMI at baseline $\left(\mathrm{kg} / \mathrm{m}^{2}\right)$} \\
\hline & \multicolumn{2}{|l|}{$<25.0$} & \multicolumn{2}{|c|}{$25.0-29.9$} & \multicolumn{2}{|c|}{$30.0-34.9$} & \multicolumn{2}{|c|}{$\geq 35.0$} & \multicolumn{2}{|l|}{ Total } \\
\hline & 18,332 & 55.2 & 11,900 & 35.9 & 2,447 & 7.4 & 505 & 1.5 & 33,184 & 100.0 \\
\hline \multicolumn{11}{|l|}{ Age at baseline, years $(n, \%)^{a}$} \\
\hline 30 & 3,161 & 65.6 & 1,345 & 27.9 & 257 & 5.3 & 57 & 1.2 & 4,820 & 100.0 \\
\hline 40 & 8,137 & 58.0 & 4,700 & 33.5 & 972 & 6.9 & 214 & 1.5 & 14,023 & 100.0 \\
\hline 50 & 7,034 & 49.0 & 5,855 & 40.8 & 1,218 & 8.5 & 234 & 1.6 & 14,341 & 100.0 \\
\hline \multicolumn{11}{|l|}{$\operatorname{Sex}(n, \%)^{a}$} \\
\hline Men & 7,186 & 46.5 & 6,986 & 45.2 & 1,147 & 7.4 & 140 & 0.9 & 15,459 & 100.0 \\
\hline Women & 11,146 & 62.9 & 4,914 & 27.7 & 1,300 & 7.3 & 365 & 2.1 & 17,725 & 100.0 \\
\hline BMI at baseline, $\mathrm{kg} / \mathrm{m}^{2}$ (mean, SD) & 22.5 & 1.7 & 26.9 & 1.3 & 31.8 & 1.3 & 37.9 & 3.0 & 25.0 & 3.6 \\
\hline BMl at 10 year follow-up, $\mathrm{kg} / \mathrm{m}^{2}$ (mean, SD) & 23.9 & 2.4 & 28.2 & 2.5 & 33.1 & 3.2 & 39.0 & 5.0 & 26.3 & 4.1 \\
\hline Change in BMl between baseline and 10 year follow-up, $\Delta \mathrm{kg} / \mathrm{m}^{2}$ (mean, SD) & +1.4 & 1.8 & +1.2 & 2.2 & +1.3 & 2.9 & +1.1 & 4.5 & +1.3 & 2.1 \\
\hline $\begin{array}{l}\text { Relative weight change between baseline and } 10 \text { year follow-up, as \% of baseline } \\
\text { weight (mean, SD) }\end{array}$ & +5.5 & 8.1 & +3.8 & 8.0 & +3.3 & 9.1 & +2.3 & 11.5 & +4.7 & 8.3 \\
\hline \multicolumn{11}{|l|}{ Baseline capillary plasma glucose concentration, mmol/L (mean, SD) } \\
\hline Fasting & 5.2 & 0.6 & 5.4 & 0.6 & 5.4 & 0.6 & 5.5 & 0.7 & 5.3 & 0.6 \\
\hline 2-h value & 6.3 & 1.2 & 6.4 & 1.3 & 6.6 & 1.5 & 6.9 & 1.4 & 6.4 & 1.3 \\
\hline \multicolumn{11}{|l|}{ IGT (n, \%) } \\
\hline At baseline & 354 & 1.9 & 363 & 3.1 & 142 & 5.8 & 35 & 6.9 & 894 & 2.7 \\
\hline At 10 year follow-up & 900 & 4.9 & 966 & 8.1 & 304 & 12.4 & 70 & 13.9 & 2,240 & 6.8 \\
\hline \multicolumn{11}{|l|}{ IFG $(n, \%)$} \\
\hline At baseline & 763 & 4.2 & 910 & 7.6 & 236 & 9.6 & 69 & 13.7 & 1,978 & 6.0 \\
\hline At 10 year follow-up & 1,641 & 9.0 & 1,414 & 11.9 & 338 & 13.8 & 81 & 16.0 & 3,474 & 10.5 \\
\hline \multicolumn{11}{|l|}{ Year at baseline $(n, \%)^{a}$} \\
\hline 1990-1994 & 7,479 & 60.3 & 4,014 & 32.4 & 771 & 6.2 & 144 & 1.2 & 12,408 & 100.0 \\
\hline 1995-1999 & 8,173 & 53.2 & 5,765 & 37.5 & 1,177 & 7.7 & 248 & 1.6 & 15,363 & 100.0 \\
\hline 2000-2003 & 2,680 & 49.5 & 2,121 & 39.2 & 499 & 9.2 & 113 & 2.1 & 5,413 & 100.0 \\
\hline \multicolumn{11}{|l|}{ Education (n, \%) } \\
\hline Primary & 6,435 & 35.1 & 5,226 & 43.9 & 1,163 & 47.5 & 260 & 51.5 & 13,084 & 39.4 \\
\hline Any secondary & 6,436 & 35.1 & 4,037 & 33.9 & 838 & 34.2 & 170 & 33.7 & 11,481 & 34.6 \\
\hline Any tertiary & 5,461 & 29.8 & 2,637 & 22.2 & 446 & 18.2 & 75 & 14.9 & 8,619 & 26.0 \\
\hline \multicolumn{11}{|l|}{ Marital status at baseline $(n, \%)$} \\
\hline Single/Widowed/Divorced & 2,951 & 16.1 & 1,867 & 15.7 & 413 & 16.9 & 109 & 21.6 & 5,340 & 16.1 \\
\hline Married/Partner & 15,381 & 83.9 & 10,033 & 84.3 & 2,034 & 83.1 & 396 & 78.4 & 27,844 & 83.9 \\
\hline Family history of diabetes $(n, \%)$ & 2,699 & 14.7 & 2,284 & 19.2 & 585 & 23.9 & 116 & 23.0 & 5,684 & 17.1 \\
\hline Tobacco use at baseline $(n, \%)$ & 5,839 & 31.9 & 4,033 & 33.9 & 782 & 32.0 & 135 & 26.7 & 10,789 & 32.5 \\
\hline Current smokers & 4,017 & 21.9 & 2,469 & 20.7 & 498 & 20.4 & 102 & 20.2 & 7,086 & 21.4 \\
\hline Current snuff users & 2,380 & 13.0 & 2,094 & 17.6 & 383 & 15.7 & 45 & 8.9 & 4,902 & 14.8 \\
\hline
\end{tabular}

Percentages calculated in the column except where otherwise indicated

Diabetes, IGT and IFG based on OGTT

BMI Body mass index, IFG Impaired Fasting Glycaemia, IGT Impaired Glucose Tolerance, OGTT Oral glucose tolerance test, SD Standard deviation

aPercentages calculated across the row 


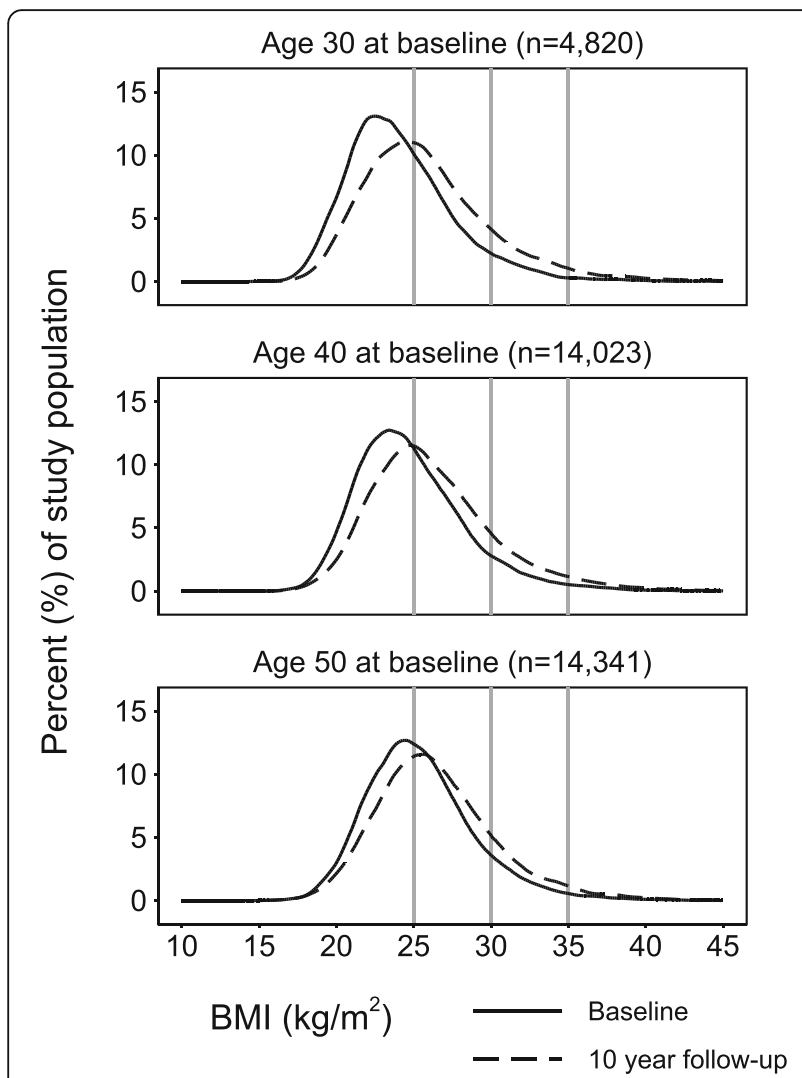

Fig. 1 Crude distribution of BMI at baseline (solid line) and 10 year follow-up (dashed line), by age at baseline. Västerbotten Intervention Programme 1990-2013. Horizontal grey lines indicate cut-off points for BMl categories $\left(25.0 ; 30.0 ; 35.0 \mathrm{~kg} / \mathrm{m}^{2}\right.$ ). Mean (SD) BMI at baseline for ages 30, 40 and 50 was 24.2 (3.6), 24.9 (3.6) and $25.5(3.6) \mathrm{kg} / \mathrm{m}^{2}$, respectively, whereas mean (SD) BMl at 10 year follow-up was $25.9(4.2), 26.3(4.2)$ and $26.5(4.0) \mathrm{kg} / \mathrm{m}^{2}$, respectively. BMI Body Mass Index

relative weight loss (OR 0.79 ( $95 \%$ CI $0.26,2.41)$ for -3.0 to $-7.0 \%$ weight) (Table 3 ). Overall results were not affected by excluding participants who were ever underweight (data not shown).

PAF results for population shift or maintenance of weight were very similar when defining weight change as absolute BMI change or weight change relative to baseline weight (Table 4). Overall, about 1 in 5 diabetes cases could be prevented if weight in middle age was maintained at the population level; PAF $21.9 \%$ (95\% CI 15.8, $27.6 \%$ ) and $22.0 \%$ (95\% CI 15.5, 28.0\%), for maintenance defined as BMI $\pm 1.0 \mathrm{~kg} / \mathrm{m}^{2}$ or weight $\pm 3.0 \%$, respectively (i). About 2 in 5 cases could be prevented if the population distribution of weight was shifted downward by the equivalent to $5 \pm 2 \%$ or $1.5 \pm 0.5 \mathrm{~kg} / \mathrm{m}^{2}$; PAF $42.4 \%$ (95\% CI $24.3,56.1 \%)$ and $38.2 \%$ (95\% CI 23.4, 50.0\%), respectively (ii). As there was no overall benefit with regards to diabetes risk associated with relative weight loss for normal weight participants, we repeated PAF calculations for overweight or obese participants only (PAFs refer to all diabetes cases); PAF $14.3 \%$ (95\% CI 8.9, 19.1\%) for weight maintenance $\left( \pm 1 \mathrm{~kg} / \mathrm{m}^{2}\right)$ (i), and PAF $23.3 \%$ (95\% CI 7.6, 35.0\%) for population distribution shift of - 1.0 to $-2.0 \mathrm{~kg} / \mathrm{m}^{2}$ in those with $\geq 25.0 \mathrm{~kg} / \mathrm{m}^{2}$ at baseline (ii) (data not shown). Overall, $29.6 \%$ of the eligible participants at baseline were not followed up (includes deaths and those who moved out of Västerbotten county during the study period). Participants lost to follow-up had higher average baseline BMI (25.6 vs. $\left.25.1 \mathrm{~kg} / \mathrm{m}^{2}\right)$ and were more likely to have IGT or IFG at baseline (40.0 and 35.6\% not followed up, respectively). In addition, we excluded $n=2,496$ due to missing, incomplete or erroneous data on height/ weight or co-variates. There was no difference between the participants with complete and missing data with regards to proportion with diabetes, IGT or IFG at baseline $(p=0.799)$ or at 10 year follow-up $(p=0.371)$, or with regards to average change in BMI between baseline and follow-up $(p=0.819$, for $n=1,423$ who had BMI data available but were missing co-variate data).

\section{Discussion}

In this population-based observational cohort study of more than 33,000 participants we have shown that there is a strong association between primary weight maintenance or moderate weight loss and decreased diabetes risk. By estimating PAFs we have also shown that if mean population weight could be shifted downwards by between 1.0 and $2.0 \mathrm{~kg} / \mathrm{m}^{2}, 2$ in 5 diabetes cases could be prevented. This is equivalent to weight loss of between 3.0 and $6.0 \mathrm{~kg}$ for an individual measuring $172.5 \mathrm{~cm}$ (the average adult height in Sweden [24]).

Previous trials of lifestyle interventions in high-risk groups (with IGT and high BMI) have achieved average weight loss of 3-6 $\mathrm{kg}[4,5]$, but these intensive health professional-led interventions are costly and could not be delivered at the necessary scale for the whole population at high risk. A more scalable high-risk approach is to use community-based commercial weight loss programmes. A recent study estimated that overweight and obese individuals who completed a 12-week commercial weight loss programme after referral from the NHS, achieved on average $-5.6 \%$ body weight loss [25]. Based on our data, we can estimate that if all individuals in the population with $\mathrm{BMI} \geq 30.0 \mathrm{~kg} / \mathrm{m}^{2}$ were enrolled in such a programme, and assuming the effect could be sustained over 10 years, an estimated $8.2 \%$ of diabetes cases could be prevented. Considering only about half of participants in trials of behavioural weight loss interventions maintain weight loss for $>1$ year [26], this is likely greatly overestimated. However, the estimate of $8.2 \%$ of diabetes cases prevented if all individuals with BMI $\geq 30.0 \mathrm{~kg} / \mathrm{m}^{2}$ were referred to a commercial weight loss programme should be contrasted to e.g., the 
Table 2 Cumulative incidence proportion of diabetes at 10 year follow-up by BMI category at baseline. Västerbotten Intervention Programme 1990-2013

\begin{tabular}{|c|c|c|c|c|c|c|c|c|c|c|c|c|}
\hline & \multicolumn{12}{|c|}{ BMl at baseline $\left(\mathrm{kg} / \mathrm{m}^{2}\right)$} \\
\hline & \multicolumn{3}{|l|}{$<25.0$} & \multicolumn{3}{|l|}{$25.0-29.9$} & \multicolumn{3}{|l|}{$30.0-34.9$} & \multicolumn{3}{|l|}{$\geq 35.0$} \\
\hline & Total (n) & $\begin{array}{l}\text { Diabetes } \\
\text { events ( } n)\end{array}$ & $\%$ & Total (n) & $\begin{array}{l}\text { Diabetes } \\
\text { events (n) }\end{array}$ & $\%$ & Total (n) & $\begin{array}{l}\text { Diabetes } \\
\text { events (n) }\end{array}$ & $\%$ & Total (n) & $\begin{array}{l}\text { Diabetes } \\
\text { events ( } n \text { ) }\end{array}$ & $\%$ \\
\hline Total & 18,332 & 324 & 1.8 & 11,900 & 500 & 4.2 & 2,447 & 211 & 8.6 & 505 & 52 & 10.3 \\
\hline \multicolumn{13}{|l|}{ Sex } \\
\hline Men & 7,186 & 154 & 2.1 & 6,986 & 316 & 4.5 & 1,147 & 118 & 10.3 & 140 & 18 & 12.9 \\
\hline Women & 11,146 & 170 & 1.5 & 4,914 & 184 & 3.7 & 1,300 & 93 & 7.2 & 365 & 34 & 9.3 \\
\hline \multicolumn{13}{|l|}{ Age at baseline } \\
\hline 30 & 3,161 & 27 & 0.9 & 1,345 & 20 & 1.5 & 257 & 8 & 3.1 & 57 & 4 & 7.0 \\
\hline 40 & 8,137 & 93 & 1.1 & 4,700 & 141 & 3.0 & 972 & 82 & 8.4 & 214 & 23 & 10.7 \\
\hline 50 & 7,034 & 204 & 2.9 & 5,855 & 339 & 5.8 & 1,218 & 121 & 9.9 & 234 & 25 & 10.7 \\
\hline \multicolumn{13}{|c|}{ BMI at 10 year follow-up, $\mathrm{kg} / \mathrm{m}^{2}$} \\
\hline$<25.0$ & 12,665 & 170 & 1.3 & 976 & 21 & 2.2 & 23 & 1 & 4.3 & 2 & 0 & 0.0 \\
\hline $25.0-29.9$ & 5,481 & 143 & 2.6 & 8,397 & 314 & 3.7 & 317 & 12 & 3.8 & 17 & 1 & 5.9 \\
\hline $30.0-34.9$ & 173 & 9 & 5.2 & 2,385 & 144 & 6.0 & 1,502 & 118 & 7.9 & 65 & 4 & 6.2 \\
\hline$\geq 35.0$ & 13 & 2 & 15.4 & 142 & 21 & 14.8 & 605 & 80 & 13.2 & 421 & 47 & 11.2 \\
\hline \multicolumn{13}{|c|}{ Weight change between baseline and 10 year follow-up, relative to baseline weight } \\
\hline Large gain $(>+7.0 \%)$ & 6,745 & 157 & 2.3 & 3,559 & 199 & 5.6 & 772 & 91 & 11.8 & 165 & 21 & 12.7 \\
\hline $\begin{array}{l}\text { Moderate gain } \\
(+3.0 \text { to }+7.0 \%)\end{array}$ & 4,346 & 72 & 1.7 & 2,632 & 112 & 4.3 & 494 & 43 & 8.7 & 84 & 10 & 11.9 \\
\hline Maintenance $( \pm 3.0 \%)$ & 5,111 & 65 & 1.3 & 3,755 & 139 & 3.7 & 679 & 59 & 8.7 & 118 & 14 & 11.9 \\
\hline $\begin{array}{l}\text { Moderate loss } \\
(-3.0 \text { to }-7.0 \%)\end{array}$ & 1,423 & 22 & 1.5 & 1,135 & 32 & 2.8 & 242 & 9 & 3.7 & 45 & 5 & 11.1 \\
\hline Large loss (> -7.0\%) & 707 & 8 & 1.1 & 819 & 18 & 2.2 & 260 & 9 & 3.5 & 93 & 2 & 2.2 \\
\hline
\end{tabular}

$B M I$ Body mass index

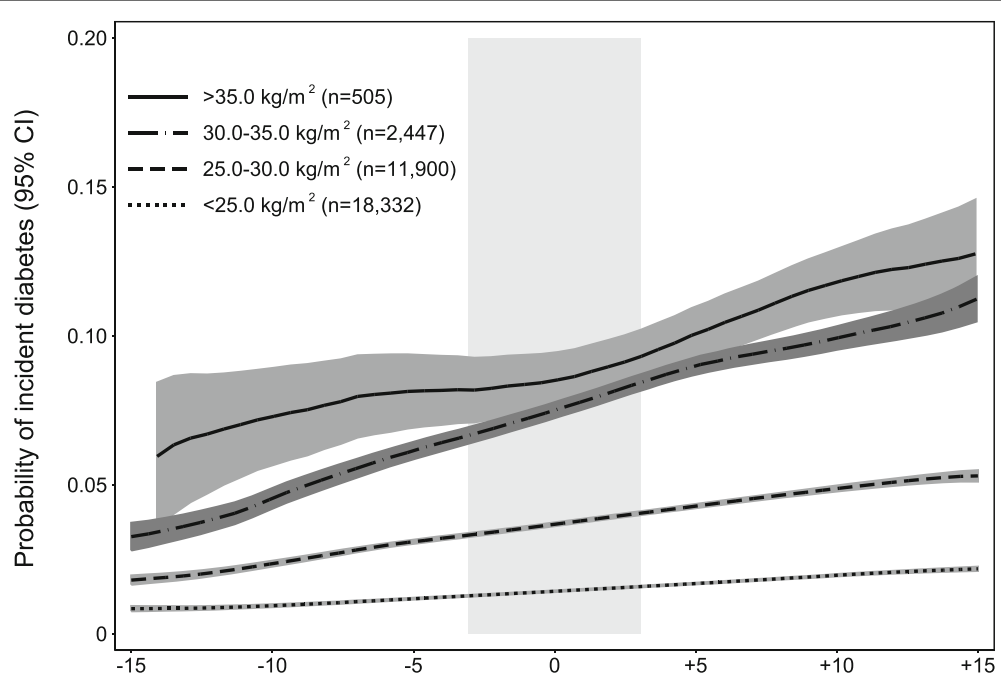

Relative weight change baseline to 10 year follow-up, as $\%$ of baseline weight

Fig. 2 Modelled estimated probability and $95 \% \mathrm{Cl}$ of incident diabetes detected at 10 year follow-up by relative weight change between baseline and 10 year follow-up, and BMI category at baseline (model 4). Västerbotten Intervention Programme 1990-2013. The grey vertical bar indicates weight maintenance ( $\pm 3 \%)$. Estimated probabilities adjusted for absolute BMI at baseline (continuous) and the co-variates sex, age at baseline (30, 40 or 50 years), calendar year at baseline (continuous), educational level, marital status, family history of diabetes and tobacco use. BMI Body Mass Index, Cl Confidence Interval 
Table 3 Association between weight change over 10 years and diabetes risk. Västerbotten Intervention Programme 1990-2013

\begin{tabular}{|c|c|c|c|c|c|c|c|c|}
\hline & \multicolumn{8}{|c|}{ BMI at baseline $\left(\mathrm{kg} / \mathrm{m}^{2}\right)$} \\
\hline & \multicolumn{2}{|l|}{$<25.0$} & \multicolumn{2}{|c|}{$25.0-29.9$} & \multicolumn{2}{|c|}{$30.0-34.9$} & \multicolumn{2}{|c|}{$\geq 35.0$} \\
\hline & OR & $95 \% \mathrm{Cl}$ & $\mathrm{OR}$ & $95 \% \mathrm{Cl}$ & OR & $95 \% \mathrm{Cl}$ & OR & $95 \% \mathrm{Cl}$ \\
\hline \multicolumn{9}{|l|}{ BMI at 10 year follow-up (model 1) } \\
\hline$<25.0$ & 1.00 & Ref & 0.63 & $0.40,0.98$ & 0.78 & $0.10,5.94$ & - & \\
\hline $25.0-29.9$ & 1.71 & $1.35,2.16$ & 1.00 & Ref & 0.47 & $0.26,0.87$ & 0.47 & $0.06,3.70$ \\
\hline $30.0-34.9$ & 4.18 & $2.07,8.43$ & 1.62 & $1.31,2.01$ & 1.00 & Ref & 0.53 & $0.18,1.54$ \\
\hline$\geq 35.0$ & 19.52 & $4.16,91.49$ & 5.17 & $3.14,8.50$ & 1.87 & $1.37,2.56$ & 1.00 & Ref \\
\hline \multicolumn{9}{|c|}{ Continuous change in BMl, per unit BMI $\left(1 \mathrm{~kg} / \mathrm{m}^{2}\right)$ (model 2) } \\
\hline All & 1.24 & $1.18,1.31$ & 1.18 & $1.14,1.23$ & 1.17 & $1.11,1.23$ & 1.13 & $1.05,1.21$ \\
\hline \multicolumn{9}{|l|}{ Age at baseline } \\
\hline 30 & 1.11 & $0.94,1.30$ & 1.08 & $0.90,1.28$ & 1.02 & $0.82,1.26$ & 1.24 & $1.00-1.54$ \\
\hline 40 & 1.28 & $1.17,1.39$ & 1.21 & $1.14,1.29$ & 1.16 & $1.07,1.25$ & 1.10 & $1.00-1.22$ \\
\hline 50 & 1.26 & $1.18,1.35$ & 1.18 & $1.12,1.24$ & 1.19 & $1.10,1.28$ & 1.09 & $0.97-1.22$ \\
\hline \multicolumn{9}{|c|}{ Weight change between baseline and 10 year follow-up, relative to baseline weight (model 3) } \\
\hline Large gain $(>+7.0 \%)$ & 2.18 & $1.63,2.93$ & 1.76 & $1.40,2.21$ & 1.65 & $1.16,2.35$ & 1.15 & $0.55,2.44$ \\
\hline Moderate gain (+3.0 to $+7.0 \%)$ & 1.39 & $0.99,1.95$ & 1.16 & $0.90,1.50$ & 0.99 & $1.65,1.61$ & 1.02 & $0.42,2.49$ \\
\hline Maintenance $( \pm 3.0 \%)$ & 1.00 & Ref & 1.00 & Ref & 1.00 & Ref & 1.00 & Ref \\
\hline Moderate loss (-3.0 to $-7.0 \%)$ & 1.24 & $0.76,2.03$ & 0.72 & $0.48,1.06$ & 0.38 & $0.19,0.79$ & 0.79 & $0.26,2.41$ \\
\hline Large loss (> -7.0\%) & 0.87 & $0.42,1.84$ & 0.61 & $0.37,1.01$ & 0.41 & $0.20,0.84$ & 0.12 & $0.02,0.54$ \\
\hline
\end{tabular}

Estimates adjusted for BMI at baseline (continuous) and the co-variates sex, age at baseline (30, 40 or 50 years), calendar year at baseline (continuous), educational level, marital status, family history of diabetes and tobacco use

$B M I$ Body mass index, $\mathrm{Cl}$ Confidence interval, OR Odds ratio

estimated $21.9 \%$ of cases that could be prevented if we achieved population wide weight maintenance $\left( \pm 1 \mathrm{~kg} / \mathrm{m}^{2}\right)$, clearly illustrating the relative potential of a populationbased approach in addition to an intervention targeted to individuals above a defined risk thresh-hold.
We have also shown that as many as 1 in 5 diabetes cases could be prevented if, at a population level, weight was maintained in adulthood. While primary weight maintenance in adulthood is challenging [27], it should be considered in contrast to the even more difficult

Table 4 Overall association between change in BMl or relative weight and diabetes risk, and population attributable fractions for maintenance or decrease in weight over 10 years. Västerbotten Intervention Programme 1990-2013

\begin{tabular}{|c|c|c|c|c|c|c|c|c|}
\hline & \multirow{2}{*}{$\begin{array}{l}\text { Total } \\
\text { (n) }\end{array}$} & \multirow{2}{*}{$\begin{array}{l}\text { Diabetes } \\
\text { events } \\
\text { (n) }\end{array}$} & \multirow[t]{2}{*}{$\%$} & \multirow[t]{2}{*}{ OR } & \multirow[t]{2}{*}{$95 \% \mathrm{Cl}$} & \multicolumn{3}{|l|}{ PAF } \\
\hline & & & & & & Model $^{a}$ & $(\%)$ & $95 \% \mathrm{Cl}$ \\
\hline \multicolumn{9}{|c|}{ Change in BMl between baseline and 10 year follow-up, $\Delta \mathrm{kg} / \mathrm{m}^{2}$ (mean, SD) } \\
\hline Any gain $\left(>+1.0 \mathrm{~kg} / \mathrm{m}^{2}\right)$ & 17,876 & 701 & 3.9 & 1.52 & $1.32,1.74$ & - & - & \\
\hline Maintenance $\left( \pm 1.0 \mathrm{~kg} / \mathrm{m}^{2}\right)$ & 12,020 & 317 & 2.6 & 1.00 & Ref & $\mathrm{i}$ & 21.9 & $15.8,27.6$ \\
\hline Moderate loss $\left(-1.0\right.$ to $\left.-2.0 \mathrm{~kg} / \mathrm{m}^{2}\right)$ & 1,923 & 45 & 2.3 & 0.72 & $0.52,0.99$ & ii & 42.4 & $24.3,56.1$ \\
\hline Large loss $\left(>-2.0 \mathrm{~kg} / \mathrm{m}^{2}\right)$ & 1,365 & 24 & 1.8 & 0.39 & $0.25,0.60$ & iii & 68.6 & $53.5,78.9$ \\
\hline \multicolumn{9}{|c|}{ Weight change between baseline and 10 year follow-up, relative to baseline weight } \\
\hline Any gain $(>+3.0 \%)$ & 18,797 & 705 & 3.8 & 1.51 & $1.31,1.75$ & - & - & \\
\hline Maintenance $( \pm 3.0 \%)$ & 9,663 & 277 & 2.9 & 1.00 & Ref & i & 22.0 & $15.5,28.0$ \\
\hline Moderate loss (-3.0 to $-7.0 \%)$ & 2,845 & 68 & 2.4 & 0.76 & $0.58,1.00$ & ii & 38.2 & $23.4,50.0$ \\
\hline Large loss (> -7.0\%) & 1,879 & 37 & 2.0 & 0.51 & $0.36,0.73$ & iii & 57.5 & $41.8,68.9$ \\
\hline
\end{tabular}

OR estimates adjusted for BMI at baseline (continuous) and the co-variates sex, age at baseline (30, 40 or 50 years), calendar year at baseline (continuous), educational level, marital status, family history of diabetes and tobacco use

$B M I$ Body mass index, Cl Confidence interval, OR Odds ratio, PAF Population attributable fraction

${ }^{a}$ The assumed counterfactuals were: weight maintenance vs. any gain (i), moderate weight loss vs. maintenance or any gain (ii), and large weight loss vs.

moderate loss or maintenance or any gain (iii) 
challenge of weight loss and subsequent secondary weight maintenance [26]. The potential of primary weight maintenance in reducing diabetes risk and burden is an important public health message, and a population-based approach to promote primary weight maintenance (reduce or prevent weight gain in middle age) is desirable as a complement to targeting individuals at high risk.

There is some evidence that identifies potential population level targets associated with weight from modelling studies, e.g., of taxing sugar-sweetened beverages [28], and observational studies, e.g., of the association with the physical environment [29], but the results have shown limited effects. Overall, there is a lack of data available in this field. Two systematic reviews concluded that there is little evidence for community or individual level interventions with the purpose of preventing weight gain in the normal weight population [30, 31], and there has been limited success in preventing weight gain in studies that aimed more broadly to reduce risk factors for cardiovascular disease [31]. While a population-based approach for weight maintenance or moderate weight loss has considerable potential for reducing diabetes burden, single interventions are unlikely to achieve the necessary impact on weight. The barriers and facilitators associated with primary weight maintenance are complex [32], and any effective approach will require changes to policy, environments and health care systems, and incorporate multiple levels and components [33].

Several previous observational population-based studies have examined the association between different levels of weight gain and incident diabetes risk [15], but with a few exceptions [34], there has been less focus on trying to understand the association between moderate weight loss or maintenance on diabetes incidence at a population level. Several previous studies have also tried to estimate PAFs for diabetes associated with the elimination of overweight and obesity with large variation in results $[10,11]$. Koh-Banerjee and colleagues estimated the PAF for diabetes incidence associated with weight maintenance between age 21 to the participants age in 1986 ( $40-75$ years) to be $56 \%$ in a cohort of 22,171 men [14]. There are several important methodological differences between that study and the present one; for instance, we compared all who maintained their weight to those who gained $\geq 3.0 \%$ or $\geq 1.0 \mathrm{~kg} / \mathrm{m}^{2}$ whereas the authors in the previous study had a relatively higher cutoff of $\geq 7 \mathrm{~kg}$ and also included individuals who lost weight in the reference group which would have contributed to a higher estimate of relative risk (RR 3.3 vs equivalent OR $1.52 / 1.51$ in the present study (Table 4)). Ford and colleagues estimated the PAF for diabetes associated with weight maintenance over 7-13 years to be
$27 \%$ in a cohort of 8545 men and women, using a more similar cut-off of $\geq 5 \mathrm{~kg}$ for weight gain and a similar methodological approach to this study [13]. To our knowledge, the present study is the first to also estimate PAFs for moderate weight loss at a population level.

This study has several strengths, in particular the large sample size, objectively measured exposure and high quality and systematic ascertainment of the outcome of diabetes status based on OGTT. When diabetes is ascertained through self-report or from general practice medical records, there is a danger of differential over diagnosis in groups at high risk, i.e., with a high BMI. However, as all participants in VIP underwent OGTTs, the risk of surveillance (ascertainment) bias of the outcome is minimised. The large population-based sample allowed us to study effects and impact of weight change in individuals at low as well as high risk of diabetes. The fact that we studied intra-individual change in weight as opposed to between-individual difference in weight provides strong support for a causal interpretation of our results.

The primary limitation of this study was that we only had data from two time-points, 10 years apart, and were not able to at present prospectively follow up enough participants for the outcome after the weight change (e.g., to the 20-year follow-up). As one of the symptoms of diabetes is weight loss [17], our results may be somewhat attenuated since diabetes is diagnosed at the same time as the second weight measurement. Similarly, the observational nature of the study means that we cannot distinguish between intentional and unintentional weight loss, which is important with regards to overall mortality risk [35] and thus may be important with regards to diabetes risk as well. To address the potential for bias due to reverse causation we had to exclude participants who self-reported diabetes and we may thus have underestimated the prevalence of diabetes in the study population, and consequently the PAFs are also likely be somewhat underestimated. However, the prevalence of diabetes in the population was comparable to the estimated prevalence in the Swedish population [36]. The VIP protocol did not include measurement of waist circumference during the period of baseline measurements in the present study, and it was thus not possible to study change in visceral adiposity, which may have added value in additional to change in weight in relation to diabetes [37]. About one third of the eligible baseline participants could not be followed up or were excluded due to missing data; participants with IFG or IGT at baseline were more likely not be followed-up and BMI was higher in those lost compared to those who were followed up. As change in weight was associated with baseline BMI and those who were obese on average increased less in weight than normal weight participants, 
our results may have somewhat overestimated the magnitude of the association between change in weight and diabetes risk. However, since there was no evidence of an interaction between baseline BMI category and change in weight for the association with incident diabetes risk, the resulting bias is likely limited. Mean BMI in the study population $\left(25.0-26.3 \mathrm{~kg} / \mathrm{m}^{2}\right.$, age $30-60$ years) was comparable to the mean BMI in the Swedish population for ages $30-59$ years $\left(25.1-26.2 \mathrm{~kg} / \mathrm{m}^{2}\right)$ [24].

\section{Conclusions}

There is great potential from a public health perspective for diabetes prevention in promoting primary weight maintenance for the whole population, in addition to moderate weight loss in individuals with a BMI $\geq 25.0 \mathrm{~kg} /$ $\mathrm{m}^{2}$ and the current approach of targeting interventions to individuals in high risk groups.

\section{Additional file}

Additional file 1: Figure S1. Flowchart describing study population. Västerbotten Intervention Programme 1990-2013. OGTT: Oral glucose tolerance test. (PDF $129 \mathrm{~kb}$ )

\section{Abbreviations}

BMI: Body mass index; Cl: Confidence interval; IFG: Impaired fasting glycaemia; IGT: Impaired glucose tolerance; kg: Kilogram; m: Metre; OGTT: Oral glucose tolerance test; OR: Odds ratio; PAF: Population attributable fraction; RR: Relative risk; SD: Standard deviation; VIP: Västerbotten intervention programme

\section{Acknowledgements}

Not applicable.

\section{Funding}

This work was supported by the Medical Research Council [MC_UU_12015/ 4], the Swedish Council for Working Life and Social Research [FAS 2006_1512] and the Swedish Research Council [2006-21576-36119-666]. The Västerbotten Intervention Programme is financed by Västerbotten County Council. Dr Feldman is supported by the Raymond and Beverly Sackler Foundation through Churchill College, Cambridge.

\section{Availability of data and materials}

The dataset supporting the conclusions of this article is available from the Västerbotten Intervention Programme.

\section{Authors' contributions}

ALF designed the analysis plan, performed the data analyses, interpreted results and drafted and critically revised the manuscript; ALA, and SJG contributed to the analysis plan, interpreted results and critically revised the manuscript; LW and MN coordinated the data collection in the Västerbotten Intervention Study, contributed to the analysis plan and critically reviewed the manuscript; GHL, EF and PW contributed to the analysis plan and critically reviewed the manuscript. All authors approved the final manuscript.

\section{Competing interests}

ALA is principal investigator on a publicly funded trial of a commercial weight loss programme, and on a research grant from Weight Watchers International to support intervention delivery and blood sampling on this weight loss trial. SJG declares receipt of an honorarium and reimbursement of travel expenses from Eli Lilly associated with membership of an independent data monitoring committee for a randomised trial of a medication to lower glucose and receipt of honoraria for speaking at postgraduate educational meetings from Janssen and Astra Zeneca. All other authors declare no competing interests.
Consent for publication

Not applicable.

\section{Ethics approval and consent to participate}

Written informed consent was obtained from VIP participants and ethical approval was granted by the Regional Ethical Review Board, Umeå University [Dnr 08-131 M].

\section{Author details}

${ }^{1}$ MRC Epidemiology Unit, Institute of Metabolic Science, University of Cambridge, Box 285, Cambridge Biomedical Campus, Cambridge CB2 OQQ, UK. ${ }^{2}$ Department of Public Health and Clinical Medicine, Umeå University, 90187 Umeå, Sweden.

Received: 28 September 2016 Accepted: 27 January 2017

Published online: 06 February 2017

\section{References}

1. Gillies CL, Abrams KR, Lambert PC, Cooper NJ, Sutton AJ, Hsu RT, Khunti K Pharmacological and lifestyle interventions to prevent or delay type 2 diabetes in people with impaired glucose tolerance: systematic review and meta-analysis. BMJ. 2007:334(7588):299.

2. NHS England and Public Health England. National NHS Diabetes Initiative launched in major bid to prevent illness. https://www.gov.uk/government/ news/national-nhs-diabetes-initiative-launched-in-major-bid-to-preventillness (2015). [Press release published 12/03/2015]. Accessed 18 July 2016.

3. Schwarz PE, Greaves CJ, Lindstrom J, Yates T, Davies MJ. Nonpharmacological interventions for the prevention of type 2 diabetes mellitus. Nat Rev Endocrinol. 2012;8(6):363-73.

4. Knowler WC, Barrett-Connor E, Fowler SE, Hamman RF, Lachin JM, Walker EA, Nathan DM, Diabetes Prevention Program Research G. Reduction in the incidence of type 2 diabetes with lifestyle intervention or metformin. N Engl J Med. 2002;346(6):393-403.

5. Lindstrom J, Louheranta A, Mannelin M, Rastas M, Salminen V, Eriksson J, Uusitupa M, Tuomilehto J, Finnish Diabetes Prevention Study G. The Finnish diabetes prevention study (DPS): lifestyle intervention and 3-year results on diet and physical activity. Diabetes Care. 2003:26(12):3230-6.

6. Abdullah A, Peeters A, de Courten M, Stoelwinder J. The magnitude of association between overweight and obesity and the risk of diabetes: a meta-analysis of prospective cohort studies. Diabetes Res Clin Pract. 2010; 89(3):309-19.

7. Hartemink N, Boshuizen HC, Nagelkerke NJ, Jacobs MA, van Houwelingen HC. Combining risk estimates from observational studies with different exposure cutpoints: a meta-analysis on body mass index and diabetes type 2. Am J Epidemiol. 2006;163(11):1042-52.

8. Rose G. Sick individuals and sick populations. Int J Epidemiol. 1985;14(1):32-8

9. Flegal KM, Panagiotou OA, Graubard BI. Estimating population attributable fractions to quantify the health burden of obesity. Ann Epidemiol. 2015: 25(3):201-7.

10. Wilson PW, D'Agostino RB, Sullivan L, Parise H, Kannel WB. Overweight and obesity as determinants of cardiovascular risk: the Framingham experience. Arch Intern Med. 2002;162(16):1867-72.

11. Laaksonen MA, Knekt P, Rissanen H, Harkanen T, Virtala E, Marniemi J, Aromaa A, Heliovaara M, Reunanen A. The relative importance of modifiable potential risk factors of type 2 diabetes: a meta-analysis of two cohorts. Eur J Epidemiol. 2010;25(2):115-24

12. Fildes A, Charlton J, Rudisill C, Littlejohns P, Prevost AT, Gulliford MC Probability of an Obese Person Attaining Normal Body Weight: Cohort Study Using Electronic Health Records. Am J Public Health. 2015:105(9):e54-9.

13. Ford ES, Williamson DF, Liu S. Weight change and diabetes incidence: findings from a national cohort of US adults. Am J Epidemiol. 1997. 146(3):214-22.

14. Koh-Banerjee P, Wang Y, Hu FB, Spiegelman D, Willett WC, Rimm EB. Changes in body weight and body fat distribution as risk factors for clinical diabetes in US men. Am J Epidemiol. 2004;159(12):1150-9.

15. Kodama S, Horikawa C, Fujihara K, Yoshizawa S, Yachi Y, Tanaka S, Ohara N, Matsunaga S, Yamada T, Hanyu O, et al. Quantitative relationship between body weight gain in adulthood and incident type 2 diabetes: a metaanalysis. Obes Rev. 2014;15(3):202-14.

16. Norberg M, Wall S, Boman K, Weinehall L. The Västerbotten Intervention Programme: background, design and implications. Glob Health Action. 2010;3. 
17. de Fine Olivarius N, Siersma VD, Koster-Rasmussen R, Heitmann BL, Waldorff FB. Weight changes following the diagnosis of type 2 diabetes: the impact of recent and past weight history before diagnosis. results from the Danish Diabetes Care in General Practice (DCGP) study. PLoS One. 2015;10(4):e0122219.

18. World Health Organization. Definition, diagnosis and classification of diabetes mellitus and its complications. Report of a WHO Consultation. Part 1: Diagnosis and Classification of Diabetes Mellitus. Geneva: WHO; 1999. p. 1-59.

19. Alberti KG, Zimmet PZ. Definition, diagnosis and classification of diabetes mellitus and its complications. Part 1: diagnosis and classification of diabetes mellitus provisional report of a WHO consultation. Diabet Med. 1998;15(7):539-53.

20. Sorkin JD, Muller DC, Andres R. Longitudinal change in the heights of men and women: consequential effects on body mass index. Epidemiol Rev. 1999;21(2):247-60.

21. Stevens J, Truesdale KP, McClain JE, Cai J. The definition of weight maintenance. Int J Obes. 2006;30(3):391-9.

22. Rockhill B, Weinberg CR, Newman B. Population attributable fraction estimation for established breast cancer risk factors: considering the issues of high prevalence and unmodifiability. Am J Epidemiol. 1998;147(9):826-33.

23. Zhang J, Yu KF. What's the relative risk? A method of correcting the odds ratio in cohort studies of common outcomes. JAMA. 1998;280(19):1690-1.

24. Statistics Sweden. The Swedish Living Conditions Survey. http://www.scb.se/ le0101. [In Swedish, published 20/09/2013]. Accessed 11 Jan 2017.

25. Ahern AL, Olson AD, Aston LM, Jebb SA. Weight Watchers on prescription: an observational study of weight change among adults referred to Weight Watchers by the NHS. BMC Public Health. 2011;11:434.

26. Barte JC, ter Bogt NC, Bogers RP, Teixeira PJ, Blissmer B, Mori TA, Bemelmans WJ. Maintenance of weight loss after lifestyle interventions for overweight and obesity, a systematic review. Obes Rev. 2010;11(12):899-906.

27. Lindvall K, Larsson C, Weinehall L, Emmelin M. Weight maintenance as a tight rope walk - a Grounded Theory study. BMC Public Health. 2010;10:51.

28. Briggs AD, Mytton OT, Kehlbacher A, Tiffin R, Rayner M, Scarborough P. Overall and income specific effect on prevalence of overweight and obesity of 20\% sugar sweetened drink tax in UK: econometric and comparative risk assessment modelling study. BMJ. 2013;347:f6189.

29. Mackenbach JD, Rutter H, Compernolle S, Glonti K, Oppert JM, Charreire H, De Bourdeaudhuij I, Brug J, Nijpels G, Lakerveld J. Obesogenic environments: a systematic review of the association between the physical environment and adult weight status, the SPOTLIGHT project. BMC Public Health. 2014;14:233.

30. Peirson L, Douketis J, Ciliska D, Fitzpatrick-Lewis D, Ali MU, Raina P. Prevention of overweight and obesity in adult populations: a systematic review. CMAJ Open. 2014;2(4):E268-72.

31. Reeder BA, Katzmarzyk PT. Canadian task force on preventive health care. Prevention of weight gain and obesity in adults: a systematic review. 2006

32. Nafziger $A N$, Lindvall $K$, Norberg $M$, Stenlund $H$, Wall $S$, Jenkins $P L$, Pearson $T A$, Weinehall $L$. Who is maintaining weight in a middle-aged population in Sweden? A longitudinal analysis over 10 years. BMC Public Health. 2007:7:108.

33. Swinburn BA, Sacks G, Hall KD, McPherson K, Finegood DT, Moodie ML, Gortmaker SL. The global obesity pandemic: shaped by global drivers and local environments. Lancet. 2011;378(9793):804-14.

34. Mishra GD, Carrigan G, Brown WJ, Barnett AG, Dobson AJ. Short-term weight change and the incidence of diabetes in midlife: results from the Australian Longitudinal Study on Women's Health. Diabetes Care. 2007; 30(6):1418-24.

35. Harrington M, Gibson S, Cottrell RC. A review and meta-analysis of the effect of weight loss on all-cause mortality risk. Nutr Res Rev. 2009;22(1):93-108.

36. Jansson SP, Fall K, Brus O, Magnuson A, Wandell P, Ostgren CJ, Rolandsson O. Prevalence and incidence of diabetes mellitus: a nationwide populationbased pharmaco-epidemiological study in Sweden. Diabet Med. 2015; 32(10):1319-28.

37. The InterAct Consortium. Long-term risk of incident type 2 diabetes and measures of overall and regional obesity: the EPIC-InterAct case-cohort study. PLoS Med. 2012;9(6):e1001230.

\section{Submit your next manuscript to BioMed Central and we will help you at every step:}

- We accept pre-submission inquiries

- Our selector tool helps you to find the most relevant journal

- We provide round the clock customer support

- Convenient online submission

- Thorough peer review

- Inclusion in PubMed and all major indexing services

- Maximum visibility for your research

Submit your manuscript at www.biomedcentral.com/submit 